\title{
Regulation of Prorenin Secretion in Cultured Human Transfected Juxtaglomerular Cells
}

Florence Pinet, Jacques Mizrahi, Irène Laboulandine, Joël Menard, and Pierre Corvol

Institut National de la Santé et de la Recherche Médicale (INSERM Unité 36), 75005 Paris, France

\begin{abstract}
The regulation of renin secretion was studied in continuous culture of human juxtaglomerular cells (JGC), which provided a permanent source of human renin production (Pinet, $F$., M. T. Corvol, F. Dench, J. Bourguignon, J. Feunteun, J. Ménard, and P. Corvol, 1985, Proc. Natl. Acad. Sci. USA, 82:8503-8507). 95\% of the renin species secreted was prorenin, and therefore this study concerned primarily prorenin secretion. Renin production was stable, since the cells had been maintained in culture for more than two years. In culture, these human cells formed colonies of smooth musclelike cells, and electron microscopy showed the presence of cytoskeleton structures including myofibrils and attachment bodies. This human model was used to investigate the control of prorenin secretion in vitro at cellular level. Various pharmacological agents known to stimulate or inhibit renin secretion were tested in the cell cultures. The variations in prorenin secretion were measured in the supernatant. Forskolin, an independent receptor activator of adenylate cyclase, stimulated prorenin secretion in a dose-dependent manner and this stimulation was mediated by 3',5' cyclic-AMP (cAMP). Angiotensin II (AII) was found to inhibit prorenin secretion directly in a dose-dependent manner and atrial natriuretic factor (ANF), whose effects on human JGC were characterized for the first time, was also shown to exert such inhibition. When the effects of this inhibition by AII and ANF were tested on forskolin-mediated stimulation of prorenin secretion, the latter was inhibited and no change occurred in cAMP release. When JGC were treated with histamine, bradykinin, or one or two bradykinin analogues, the responses suggested that in these cells, $\mathrm{H}_{2}$-histamine receptors and kinin receptors are dependent on adenylate cyclase. One peptide, substance $P$, had an inhibitory effect on prorenin secretion but it was less important than AII and ANF. The present results demonstrate that the adenylate cyclase system of human JGC remains intact during culture and supports the hypothesis that CAMP is the second messenger and $\mathrm{Ca}_{\mathbf{i}}{ }^{2+}$, the final messenger involved in renin secretion. The cell system used here permits the evaluation of cellular responses and intracellular events in granulated cells in a human model.
\end{abstract}

\section{Introduction}

The renin-angiotensin system plays a major role in the maintenance of blood pressure and salt and water homeostasis. The

Address correspondence to Dr. Pinet, INSERM U36, Pathologie Vasculaire et Endocrinologie Rénale, 17, rue du Fer-à-Moulin, 75005 Paris, France.

Received for publication 7 January 1987 and in revised form 10 April 1987.

J. Clin. Invest.

(C) The American Society for Clinical Investigation, Inc.

0021-9738/87/09/0724/08 \$2.00

Volume 80, September 1987, 724-731 key component of this system is the enzyme renin (EC 3.4.23.15) because almost all physiological or pathophysiological alterations of the renin-angiotensin system activity are mediated by changes in the rate of renin secretion.

Renal renin is synthetized and secreted by juxtaglomerular cells (JGC). ${ }^{1}$ In vitro models for studying renin biosynthesis and its regulation are needed because of the multiple factors that influence renin production and secretion in vivo. The most suitable in vitro model appears to be the culture of highly purified JGC. Most studies of renin secretion have been performed in complex systems, such as in vivo, in the isolated perfused kidney, in kidney cortex slices and isolated glomeruli with attached afferent arterioles $(1,2)$. These systems included potential influences of endothelial, mesangial, and vascular smooth muscle cells that are located close to the JGC, and in these preparations it is impossible to measure cellular responses and intracellular events in granulated cells. Establishing JGC cultures has in the past proved difficult, mainly because of the scarcity of these cells in the kidney. Primary cultures of renin-secreting cells from the rat were recently reported by Kurtz et al. (3) to be an effective model for investigating the role of calcium and protein kinase $C(4)$ in the regulation of renin secretion. Continuous human JGC lines, producing prorenin, were obtained and provided a permanent source of renin-producing cells available for the study of prorenin regulation in vitro (5). Renin secretion is controlled by various hormonal signals of systemic or local origin. In the present study, with the availability of cultured human reninproducing cells, direct biochemical studies of their receptor system and of intracellular mechanisms were made and direct approaches were used to evaluate these cellular functions. For these purposes, we investigated the effect of different modulators of renin production and tested directly, for the first time, the hypothesis that although $3^{\prime}, 5^{\prime}$ cyclic-AMP (cAMP) acts as second messenger in stimulating renin secretion, a change in the production of cAMP by cultured human JGC is not a prerequisite for an alteration of their renin secretion rate.

\section{Methods}

\section{Cell culture}

The renin-producing human JGC described previously (5) were used between the sixth and ninth subcultures. JGC were cultured in $25-\mathrm{cm}^{2}$ flasks containing $4 \mathrm{ml}$ of Dulbecco's modified Eagle's medium (DME) supplemented with $10 \%$ fetal calf serum (FCS). Cultures were maintained at $37^{\circ} \mathrm{C}$ and the subcultures were carried out after treatment with $0.05 \%$ clostridium collagenase (Boehringer Mannheim Biochemicals, Indianapolis, IN) and $5 \mathrm{mM}$ EDTA, pH 7.5.

\section{Morphological studies}

Electron microscopy (EM) studies were performed on cells transfected by the PAS mutant (5) at confluency in subculture 3 . Cultured cells

1. Abbreviations used in this paper: AII, angiotensin II; ANF, atrial natriuretic factor; DME, Dulbecco's modified Eagle's medium; EM, electron microscopy; JGC, juxtaglomerular cell(s). 
were rinsed, fixed with $2.5 \%$ glutaraldehyde, rinsed again, and postfixed in $2 \%$ osmic acid. After another three rinses, cells were stained with $2 \%$ uranyl acetate, dehydrated first with ethanol and then with hydroxypropylmethacrylate, and embedded in Epon 812 resin. Sections 500-800-Å thick were cut horizontally with a diamond knife in an ultracut ultramicrotome (Reichert Jung, Cambridge, United Kingdom) and examined with an Elmiskop 101 electron microscope (Siemens A.G., Frankfurt, Federal Republic of Germany).

\section{Hormones and supplies}

Forskolin was obtained from Calbiochem Brand Biochemical (BeringWerke, AG, Marburg, Federal Republic of Germany). Angiotensin II (AII), bradykinin, Des[Arg]'-bradykinin, Lys-bradykinin, cimetidine, diphenhydramine, epinephrine, histamine, isoprenaline, and theophylline were purchased from Sigma Chemical Co (St. Louis, MO). Synthetic human atrial peptide Arg101 to Tyr126 (atrial natriuretic factor [ANF]) was purchased from Ciba-Geigy A.G. (Basel, Switzerland) and kindly provided by Dr. A. Kurtz (Physiologisches Institut, Zurich, Switzerland), and substance $P$ was a generous gift from Dr. D. Regoli (Dept. of Pharmacology, Sherbrook, Quebec, Canada). All other materials were obtained as described previously (5).

\section{Hormonal and pharmacological treatment}

Cells were allowed to grow to confluency. The culture medium was removed and cells were washed with two changes $(4 \mathrm{ml}$ each) of serum-free DME. The cultures were then incubated for $12 \mathrm{~h} \mathrm{in} 4 \mathrm{ml}$ of serum-free DME at $37^{\circ} \mathrm{C}$. Serum-free DME was used for the hormonal and pharmacological experiments to avoid the presence of hormones in the serum that could have masked the effects of additional hormones and pharmacologic agents added in our experiments (6). The hormones were dissolved in $\mathrm{Ca}^{2+}$ and $\mathrm{Mg}^{2+}$ free Gey's balanced salt solution, except for forskolin, which was dissolved in ethanol. The hormones were added to $4 \mathrm{ml}$ of serum-free medium and both control and treated cultures were incubated for $6 \mathrm{~h}$ at $37^{\circ} \mathrm{C}$. The medium was removed, centrifuged, and stored at $-20^{\circ} \mathrm{C}$. The cells were again incubated with $4 \mathrm{ml}$ of DME containing $10 \%$ FCS to test their capacity to restore their basal renin production.

\section{Cell culture conditions}

The renin-producing human JGC were used at the ninth subculture. After the seventh subculture, examination by phase-contrast microscopy showed that the mast cells had disappeared, but no EM study was performed at this stage of subculture. Histamine production was measured throughout subculture. This production was important in primary culture but a sharp decrease in the histamine level was measured in the different subcultures until it became undetectable (data not shown), showing that no interference of mast cells could occur in the experiments concerning regulation.

The effects of different hormones on prorenin secretion in cultured human JGC were studied for $6 \mathrm{~h}$. Prorenin secretion by these cells was dependent on the percentage of FCS added to the medium. With 5\% FCS, prorenin secretion measured decreased by half in $24 \mathrm{~h}$; cells cultured in serum-free medium produced $75 \%$ less renin than those cultured in $10 \%$ FCS. For hormonal treatment, it was necessary to incubate the cells for $12 \mathrm{~h}$ in serum-free medium before the experiment to obtain a stable basal level of prorenin secretion. After $6 \mathrm{~h}$ of pharmacological treatment, basal prorenin secretion and its alterations were easily detectable by enzyme-linked immunosorbent assay (ELISA) (7).

\section{Biochemical assays}

Renin assay. Renin production in the culture medium was measured by direct immunoassay. Direct total renin, i.e., active plus inactive, was determined by ELISA (7). The sensitivity of this assay is $1 \mathrm{pg} / 50 \mu \mathrm{l}$.

cAMP assay. Release of cAMP into the culture medium was determined by cAMP radioimmunoassay (RIA) (Immunotech SA, Luminy, France) (8). The sensitivity of this assay is $2 \mathrm{nM}$.

Histamine assay. The production of histamine was examined in different subcultures of JGC to show the relation between juxtaglo- merular and mast cells, and was determined by RIA (Immunotech SA). The sensitivity of this assay is $0.1 \mathrm{nM}$.

\section{Calculations}

For each experiment, the initial total prorenin secretion by the JGC was determined when the cells were at the same stage of confluency. Since the initial total prorenin secretion varied with the duration of culture, the results were standardized by conversion to percent changes versus the controls for the sole purpose of comparing the findings for the different cell cultures used for replicate experiments.

\section{Results}

Morphology of cells in culture. Cells secreting prorenin continuously were obtained by transfection with SV40 mutants. These cells had been maintained in culture for more than two years at the time of writing (November, 1986). They formed colonies of smooth, musclelike cells (Fig. $1 A$ ). In an EM study performed on cells after three subcultures, the presence of myofibrils at the periphery of the cells and few dark granules around the nucleus were observed (Fig. $1 B$ ). The inset to Fig. 1 $B$ shows details of the myofibrils in elongated cells, including their striated appearance, which resulted from the regular arrangement of myofilaments. In phase-contrast microscopy, the renin-producing human JGC in subculture 9 had the same morphology as after transfection.

Cell culture conditions. The cells were cultured exactly as described by Pinet et al. (5). The rate of renin production of confluent cells, which represented three million cells per $25-\mathrm{cm}^{2}$ flask, was relatively stable and ranged from 50 to 100 $\mathrm{pg} / \mathrm{ml}$ per $24 \mathrm{~h}$ between subcultures 6 and 9 . The prorenin secretion before the hormonal or pharmacological experiments was $88 \pm 3 \mathrm{pg} / \mathrm{ml}$ per $24 \mathrm{~h}(n=6)$ and after the experiments was $91 \pm 21 \mathrm{pg} / \mathrm{ml}$ per $24 \mathrm{~h}(n=6)$. The cells could be frozen and thawed at each passage without losing their capacity to divide and to produce renin.

Theophylline was used in all cell culture experiments. A high concentration of theophylline $\left(10^{-4} \mathrm{M}\right)$ was needed to inhibit phosphodiesterase activities effectively. Basal prorenin secretion by cells that were not treated with theophylline and were incubated for $6 \mathrm{~h}$ in serum-free medium was $77 \pm 11$ $\mathrm{pg} / \mathrm{ml}$ per $24 \mathrm{~h}(n=14)$ versus $80 \pm 12 \mathrm{pg} / \mathrm{ml}$ per $24 \mathrm{~h}$ with theophylline-treated cells $(n=14)$. It was found that a theophylline concentration of $10^{-4} \mathrm{M}$ did not affect prorenin secretion by JGC, even when the cAMP concentration was raised from 2 to $8 \mathrm{nM} / \mathrm{ml}$ per $24 \mathrm{~h}$ in the theophylline-treated flasks.

Effect of forskolin on prorenin secretion. To test the hypothesis that adenylate cyclase and cAMP play a role in the control of human renin secretion by JGC, the concentration dependence of the effect of forskolin on prorenin secretion was studied and the cAMP concentration in the medium measured. Accordingly, cultured human JGC were incubated for 6 $h$ with increasing concentrations of forskolin $\left(10^{-10}-10^{-5} \mathrm{M}\right)$ and a concentration of $10^{-4} \mathrm{M}$ theophylline. As shown in Fig. 2, forskolin increased prorenin secretion in a dose-dependent manner. The $50 \%$ effective dose $\mathrm{ED}_{50}$ and optimum concentration of forskolin for prorenin secretion were $4.710^{-8} \mathrm{M}$ and $10^{-5} \mathrm{M}$, respectively. The respective dose-response curves for the forskolin-induced rises in the secretion of prorenin and release of cAMP were compared and found to be parallel (Fig. 2). The $\mathrm{ED}_{50}$ and the optimum forskolin concentration for cAMP release were $5.10^{-7}$ and $10^{-5} \mathrm{M}$, respectively. 


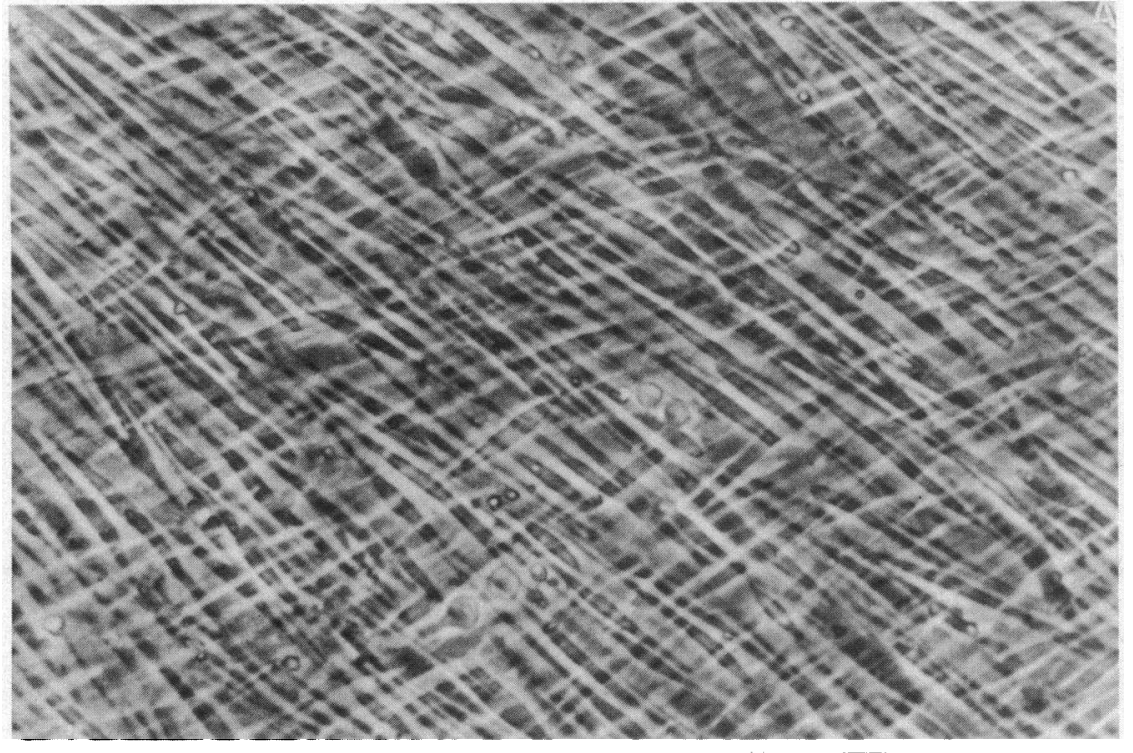

Figure 1. Phase-contrast $(A)$ and EM $(B)$ photographs of human JGC in culture. $(A)$ Elongated cells forming colonies of smooth musclelike cells $(\times 160)$. $(B)$ Elongated cells containing numerous mitochondria with dark granules and myofibrils at the periphery $(\times 8,000)$. Inset shows details of myofibrils in elongated cells $(\times 70,000)$.

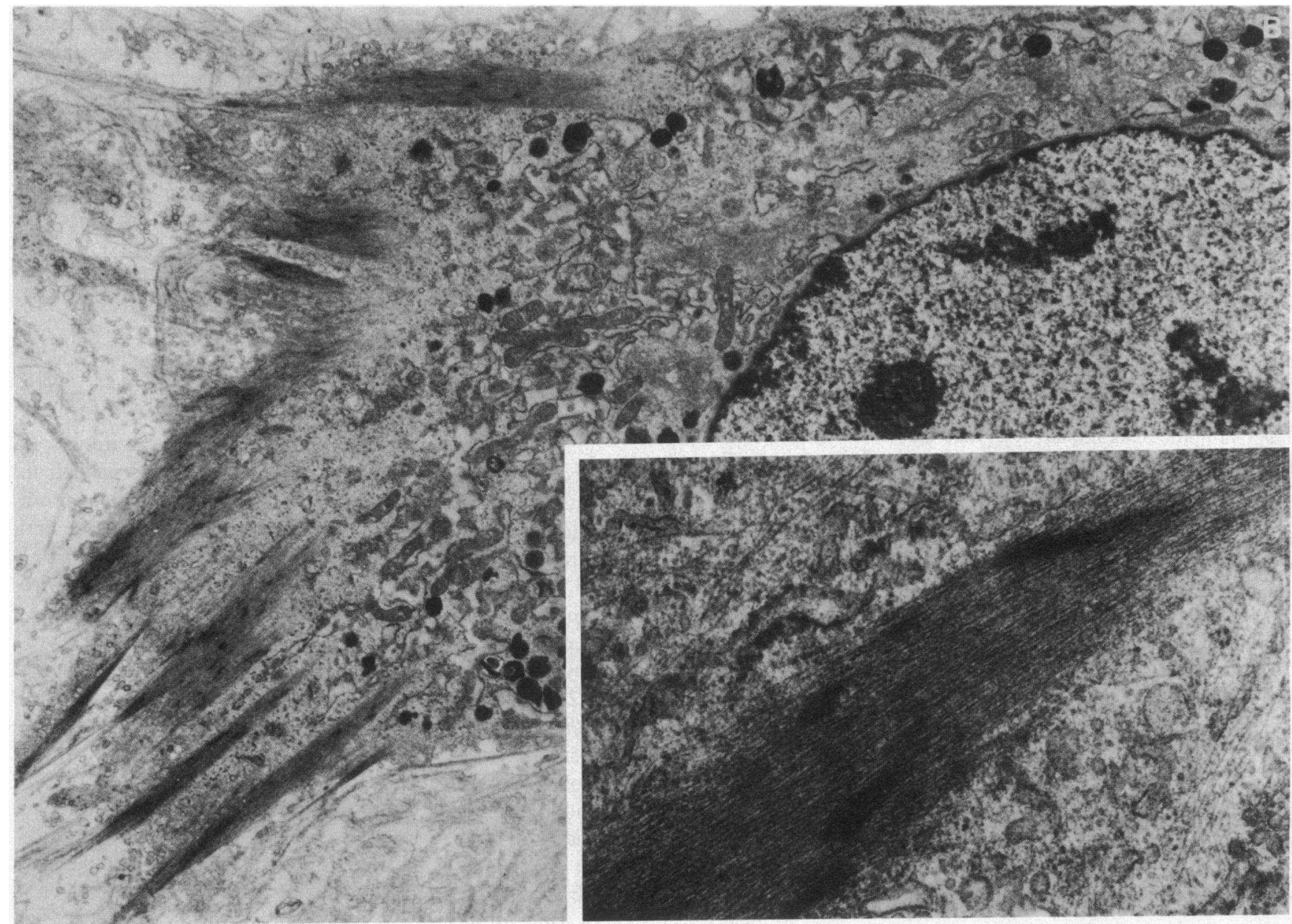

Inhibition by AII of prorenin secretion with and without its stimulation by forskolin. To evaluate the inhibitory effect of AII alone on prorenin secretion by human JGC, the latter were incubated with increasing concentrations of AII $\left(10^{-10}-10^{-6}\right.$ $\mathrm{M})$. As shown in Fig. $3 \mathrm{~A}$, AII effectively suppressed prorenin secretion in a dose-dependent manner. cAMP was undetect- able in the medium of both control and AII-treated cells (data not shown).

To evaluate the direct effect of AII on forskolin-mediated stimulation of prorenin secretion, human JGC cultures were incubated with $10^{-6} \mathrm{M}$ forskolin, $10^{-4} \mathrm{M}$ theophylline, and increasing concentrations of AII $\left(10^{-10}-10^{-6} \mathrm{M}\right)$. As shown in 


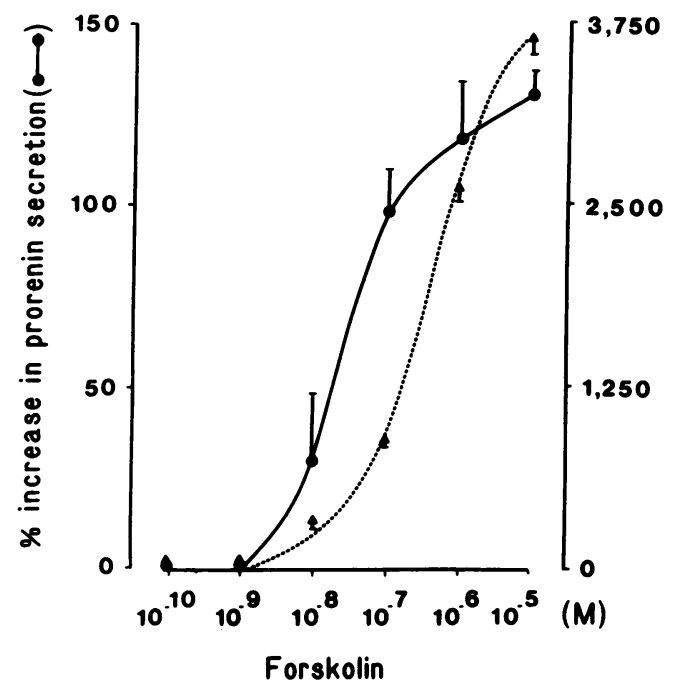

Figure 2. Effect of forskolin on prorenin secretion and cAMP release in cultured human JGC. Cultures were treated with the indicated concentrations of forskolin. The percentage of stimulation of prorenin secretion was determined as described in Methods (calculations). The points represent the means and the bars represent the standard error of renin determinations performed on four separate cell culture flasks. Each renin assay was done in duplicate. The points represent the means and the bars represent the standard error of cAMP determinations on four of the same cell culture flasks.

Fig. $3 B$, AII effectively blocked forskolin-stimulated prorenin secretion. This inhibition of prorenin secretion was compared with the cAMP release induced by forskolin in Fig. $3 C$. At concentrations of $10^{-10}-10^{-6} \mathrm{M}$, AII did not inhibit the increase of cAMP production induced by forskolin.

Effect of human ANF on prorenin secretion with and without its stimulation by forskolin. To characterize the effects on renin production of ANF, the human JGC were incubated for $6 \mathrm{~h}$ with increasing concentrations of $\operatorname{ANF}\left(10^{-10}-10^{-6} \mathrm{M}\right)$. As shown in Fig. $4 A$, ANF inhibited prorenin secretion in a dose-dependent manner. cAMP was undetectable in the medium of both control and ANF-treated cells (data not shown).

To examine the effect of ANF on forskolin-stimulated prorenin secretion, human JGC cultures were incubated with $10^{-6} \mathrm{M}$ forskolin, $10^{-4} \mathrm{M}$ theophylline, and increasing concentrations of ANF $\left(10^{-10}-10^{-6} \mathrm{M}\right)$. As shown in Fig. $4 B$, ANF effectively blocked forskolin-stimulated prorenin secretion. In Fig. $4 C$, the inhibition by ANF of this secretion was compared with the increase in cAMP release induced by forskolin. This increase was not inhibited by ANF in a dose-dependent manner (Fig. $4 \mathrm{C}$ ).

Effect of various compounds on the regulation of prorenin secretion. The model of cell culture has proved a useful tool for studying the regulation of prorenin secretion by testing the cells with the same concentration $\left(10^{-5} \mathrm{M}\right)$ of different compounds known to stimulate or inhibit this secretion in perfused kidney or cortical slices. Here, the role of $\beta$-adrenergics was studied by treating cells with isoprenaline and epinephrine. The data in Table I show that these $\beta$-adrenergics stimulated prorenin secretion and induced a parallel increase in cAMP release. Epinephrine caused smaller increases than isoprenaline in prorenin secretion and cAMP release by human JGC. The effects of histamine, histamine $\mathrm{H}_{1}$ - and $\mathrm{H}_{2}$-antagonists were studied in the attempt to define the type of receptor
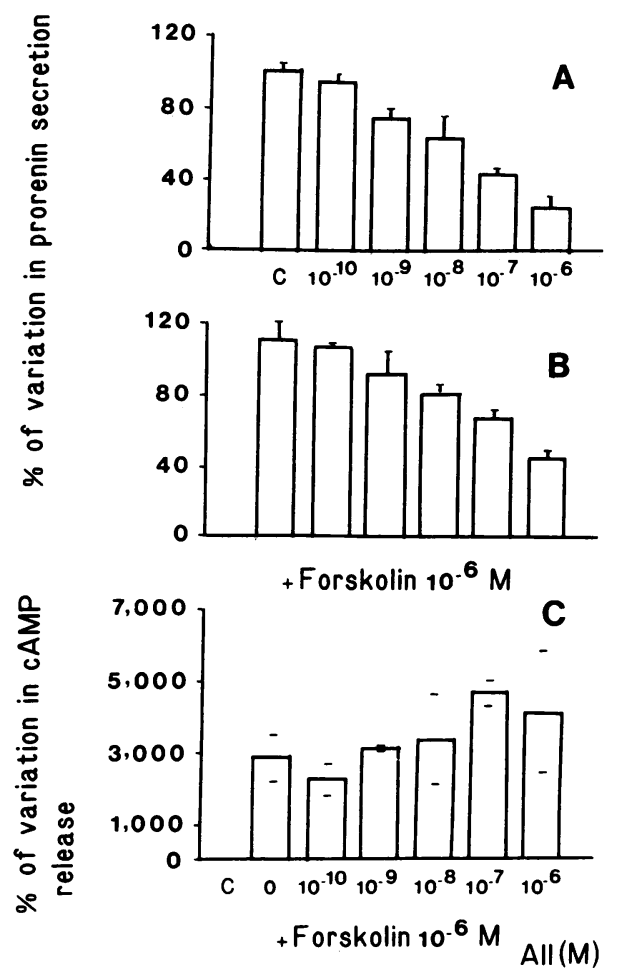

Figure 3. Effect of AII on prorenin and cAMP secretion. Cultures were treated with the indicated concentrations of AII, either alone $(A)$ or combined with $10^{-6} \mathrm{M}$ forskolin ( $B$ and $C$ ). The percentage of variation in prorenin secretion was determined as described in Methods, except for $A$, where the theophylline-treated flask (c) was at $100 \%$. The points ( $A$ and $B$ ) represent the means and the bars represent the standard error of renin determinations performed on four separate cell culture flasks. Each renin assay was done in duplicate. In two of these cell culture flasks CAMP was measured $(C)$. The individual values are indicated by the points and the mean by the bars.

involved in the renin secretion. Histamine stimulated prorenin secretion by human JGC and, as shown in Table $\mathrm{I}$, the $\mathrm{H}_{2}$-receptor antagonist cimetidine inhibited the increase in prorenin secretion observed in response to histamine by $\sim 50 \%$. The $\mathrm{H}_{1}$-antagonist diphenhydramine had little effect on histamine-induced prorenin secretion. Histamine induced an increase in cAMP release parallel to its stimulation of prorenin secretion, and the $\mathrm{H}_{2}$-receptor antagonist cimetidine inhibited cAMP release in a parallel fashion to its inhibition of prorenin secretion. As many studies have suggested that a functional relationship may exist between the kallikrein-kinin and renin-angiotensin systems, the possibility that kinins act to increase prorenin secretion in human JGC cultures was studied. Accordingly, bradykinin and two of its analogues, Lysbradykinin and Des-Arg'-bradykinin, were added to the medium. Prorenin secretion was stimulated by all three compounds in the same proportions and the range of increases is correlated with a similar range of increase in cAMP secretion. Substance $P$ induced a decrease in prorenin secretion by human JGC but did not change cAMP release.

\section{Discussion}

To our knowledge, this is the first study of the regulation of prorenin secretion in human JGC. The availability of continu- 


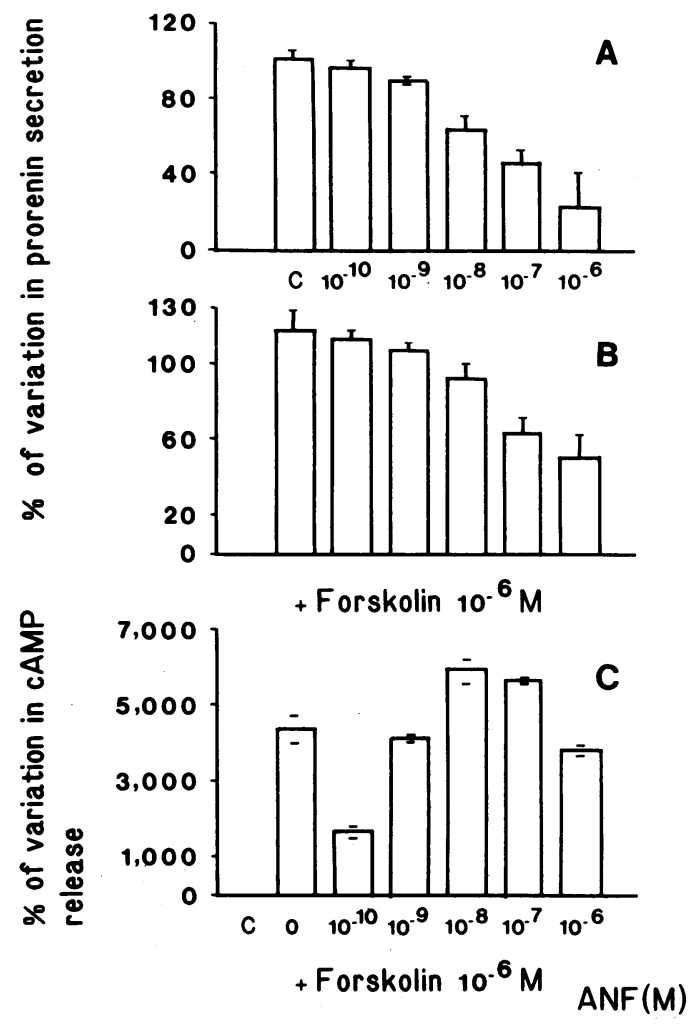

Figure 4. Effect of ANF on prorenin and cAMP secretion. Cultures were treated with the indicated concentrations of ANF, either alone $(A)$ or combined with $10^{-6} \mathrm{M}$ forskolin $(B$ and $C$ ). The percentages of variation in prorenin secretion were determined as described in Methods except for $A$, where the theophylline-treated flask (c) was at $100 \%$. The points ( $A$ and $B$ ) represent the means and the bars represent the standard error of renin determinations performed on four separate cell culture flasks. Each renin assay was done in duplicate. In two of these cell culture flasks cAMP was measured $(C)$. The individual values are indicated by the points and the mean by the bars.

Table I. Effects of Different Compounds on the Regulation of Prorenin Secretion and cAMP Release in Human JGC

\begin{tabular}{|c|c|c|}
\hline Compound $\left(10^{-5} \mathrm{M}\right)$ & $\begin{array}{l}\text { Percentage of variation } \\
\text { in prorenin secretion } \\
\text { (\%)* }\end{array}$ & $\begin{array}{l}\text { Percentage of variation } \\
\text { in the cAMP } \\
\text { concentration }(\%)^{*}\end{array}$ \\
\hline Isoprenaline & $\uparrow 79 \pm 5(n=6)$ & $\uparrow 143$ \\
\hline Epinephrine & $\uparrow 50 \pm 15(n=4)$ & $\uparrow 47$ \\
\hline Histamine & $\uparrow 48 \pm 3(n=6)$ & $\uparrow 32$ \\
\hline \multicolumn{3}{|l|}{ Histamine } \\
\hline + diphenhydramine & $\uparrow 36 \pm 9(n=6)$ & $\uparrow 52$ \\
\hline Histamine + cimetidine & $\uparrow 5 \pm 11(n=6)$ & $\uparrow 3$ \\
\hline Bradykinin & $\uparrow 43 \pm 8(n=4)$ & $\uparrow 115$ \\
\hline Lys-bradykinin & $\uparrow 38 \pm 4(n=4)$ & $\uparrow 99$ \\
\hline Des-Arg'-bradykinin & $\uparrow 51 \pm 12(n=4)$ & $\uparrow 105$ \\
\hline AII & $\downarrow 67 \pm 8(n=6)$ & 0 \\
\hline Substance $\mathbf{P}$ & $\downarrow 34 \pm 4(n=4)$ & 0 \\
\hline
\end{tabular}

* Each percentage represents the mean $\pm S E$ of determinations made on $n$ cell culture flasks. Each renin assay was made in duplicate.

₹ The percentage represents the mean of cAMP determinations made on two of these cell culture flasks. ous human renin-producing cells (5) provides a useful tool to investigate the regulation of renin production at cellular level. Cell morphology was studied in detail in different subcultures. EM studies of human JGC in the third subculture showed the presence of myofibrils. At higher magnification, attachment bodies were easily detectable in the cytoplasm of these cells. They provided mechanical support for various cellular structures and extensions and were suggestive of smooth muscle differentiation. These results are in agreement with those of Lindop et al. (9), who described the JGC as myoepithelioid cells because their morphology is intermediate between that of endocrine and smooth muscle cells. Under phase-contrast microscopy, the regular arrangement of human JGC in culture could be explained by the cytoskeleton structures present in the cytoplasm. The numerous myofibril extensions were probably due to the precoating of the culture flasks with fibronectin.

These transfected JGC produced $95 \%$ of renin in an inactive form and we can show that the species of renin produced by these cultured cells was prorenin. This is in agreement with the morphology of the cells because EM studies show that the cells contain a low content of granules. It has been suggested that the renin species in granules was active renin (9). In our systems the cells contained a few granules and renin produced was predominantly in the inactive form. In the ninth subculture, the human JGC were still producing measurable quantities of prorenin. For all the experiments concerning the regulation of prorenin secretion, the morphology of the cells was observed at the ninth subculture and was similar to that reported after transfection at the third passage (5).

The data presented in this paper described the regulation of prorenin secretion, and in particularly the effect of one mediator, cAMP. Different authors have described two pathways for renin secretion $(10,11)$ : active renin is secreted after storage in granules by a regulated pathway and prorenin is secreted directly via the constitutive pathway without storage and processing. In our model, prorenin is the major form of renin secreted. Therefore, our results about the regulation of prorenin secretion should be extrapolated with caution for active renin secretion. As previously reported by Pinet et al. (5), active renin in this preparation of human renin-producing cells represented $5 \%$ of total renin. When active renin secretion was measured after stimulation of cultures by forskolin, isoprenaline, or histamine, there was no increase of active renin compared with that of total prorenin secretion (data not shown).

In the present study, the level of cAMP represents the cAMP efflux from the JGC. Different authors $(12,13)$ have described the measurement of intra- and extracellular cAMP levels. They showed a relationship between the two pools (intra- and extracellular): cAMP accumulated within the cells appeared in the extracellular fluid after a short lag period in different cell cultures, showing that the rate of cAMP efflux was not proportional to the intracellular concentration. So, in our case, measurement of extracellular cAMP represents an indirect reflection of intracellular CAMP but permitted us to see the variations of CAMP levels under hormonal or pharmacologic agents.

The role of cAMP in the control of renin secretion has been described by Hackenthal et al. (2) in the rat using the complex model of isolated perfused kidney. These authors studied the renin release induced by forskolin, an independent receptor activator of adenylate cyclase (14), without altering the renal 
perfusate flow in the isolated perfused rat kidney, and their results supported the concept that in glomerular cells an increase in the intracellular concentration of CAMP is associated with an increase in renin release (15). However, in such experiments, we cannot rule out the possibility that in addition to JGC, forskolin stimulated other cells in the immediate vicinity, which could in turn have stimulated the JGC. In the present experiments, this hypothesis was directly tested by adding forskolin together with theophylline to JGC cultures. High concentrations of theophylline are needed to effectively inhibit phosphodiesterase activities (16). In the present cultures, theophylline increased the production of cAMP, as described by Keeton and Campbell (1), who reported that by inhibiting the degradation of CAMP in $5^{\prime}$ adenosine monophosphate, theophylline raised the cAMP concentration in granular JGC. They observed that theophylline alone did not stimulate renin release from rat renal cortical slices in vitro. In JGC cultures, we obtained the same results with no variation in prorenin secretion but an increase in cAMP. It is surprising that an important increase in CAMP release was not correlated with an increase in prorenin secretion. However, theophylline does not act at the level of the receptor and does not activate adenylate cyclase, so the increase in cAMP release represents an artificial increase in cAMP and not the activity of adenylate cyclase. We used theophylline with forskolin to potentiate the effect of this hormone known to act via cAMP. Our results demonstrate that forskolin modulates the rate of human prorenin secretion in cultured JGC in a dose-dependent manner and that the response to this hormone is mediated by cAMP. This supports the hypothesis of Churchill and Churchill (17) that cAMP has a putative role as second messenger in renin secretion. Consequently, the present results clearly establish that in granulated cells, forskolin directly stimulates prorenin secretion.

Using the same culture conditions, the direct effect of AII on human JGC could be studied for the first time. AII is known to inhibit renin secretion, probably by increasing the $\mathrm{Ca}^{++}$permeability of the cellular plasma membranes (18). Our results demonstrate that AII suppresses basal prorenin secretion in human JGC in a dose-dependent manner. The threshold of the inhibition of prorenin secretion was obtained at an AII concentration of $10^{-10} \mathrm{M}$, and the $\mathrm{IC}_{50}$ was $2 \times 10^{-8} \mathrm{M}$. In addition, AII did not alter CAMP production, as also observed by Kurtz et al. (3). The sensitivity of our cells to AII was comparable with that described in other literature models such as in vivo, kidney slices, and isolated perfused kidney (19). The higher sensitivity of AII in human JGC cultures may be due to the potential influences of the endothelial, mesangial, and vascular smooth muscle cells as well as to the macula densa that are located close to the JGC in these preparations.

The effect of ANF on prorenin secretion is still controversial. Burnett et al. (20) showed that synthetic ANF inhibited renin release from perfused dog kidney, and Opgenorth et al. (21) failed to demonstrate any such inhibition by ANF in the nonfiltering dog kidney. Villareal et al. (22) found that ANF did inhibit renin secretion in both these models described above, whereas Hackenthal et al. (23) demonstrated that ANF stimulated this secretion in isolated perfused rat kidney. In the model of rat renal cortical slices, two other groups obtained controversial results for the effect of ANF on renin secretion: Hiruma et al. (24) showed a stimulatory effect of ANF and demonstrated that the mechanism responsible was not related to any increase in endogenous cGMP nor cAMP, whereas Obana et al. (25) reported a dose-dependent inhibition by ANF of renin secretion with a fall in cAMP release and a rise in that of CGMP. The effects of ANF on human JGC were investigated in a similar study to that of AII. Synthetic ANF, identical to human $\alpha$-ANF (26), specifically inhibited prorenin secretion from human JGC in a dose-dependent manner. Again, ANF did not affect cAMP production. The present cell culture model permits us to see precisely the direct action of ANF on prorenin secretion by the JGC, without having the influence of the macula densa. In agreement with our results, Kurtz et al. (27) reported that ANF inhibited renin secretion in the JGC of the rat. All these results for cell cultures support the view that ANF suppresses renin secretion by a direct action on human and rat cells.

Two main second messengers in renin secretion have so far been reported as intracellular $\mathrm{Ca}^{2+}$ fluxes and cAMP. Here, AII and ANF did not only alter basal cAMP release but were also unable to reduce cAMP release when the cells were stimulated by forskolin, although they did reduce prorenin secretion. This shows the independent pathways of cAMP-mediated prorenin secretion by forskolin and AII, respectively, as well as the mechanism of renin inhibition by ANF. Schwertschlag and Hackenthal (5) also observed that the stimulatory effect of forskolin was inhibited by AII in the model of isolated perfused rat kidney. The fact that an alteration in the cAMP concentration is not necessary for an alteration of the renin secretion rate was also shown by Kurtz et al. (3) in rat JGC, because in these cells renin secretion was stimulated by verapamil and inhibited by AII without any change in the intracellular cAMP concentration in either case. The role of $\mathrm{Ca}^{2+}$ was investigated by Fray and Park (28) in isolated perfused rat kidney, and their results indicated that the stimulatory action of forskolin was independent of, or noncompetitive with the extracellular $\mathrm{Ca}^{++}$concentration. The principle expressed in the review by Churchill (19) is that free $\mathrm{Ca}^{++}$and cAMP are, respectively, the inhibitory and stimulatory second messengers in renin secretion. He suggested that each of these second messengers might act independently, or else sequentially, in either of two ways. Our results support the hypothesis that cAMP and $\mathrm{Ca}^{++}$act independently in the prorenin secretory process but that the inhibitory effect of the rise in $\mathrm{Ca}^{++}$ predominates over the stimulatory effect of the rise in CAMP. We investigated the role of ANF forskolin-stimulated prorenin secretion in human JGC cultures in the same way as the role of AII. ANF clearly blocked stimulation of prorenin secretion in a dose-dependent manner, and no change was observed in cAMP release. These results were not surprising, because ANF alone had no effect on cAMP release and as demonstrated by Kurtz et al. (27), the effect of ANF is mediated by cGMP.

The testing of agents known to induce renin release in different ways showed that the JGC respond to adrenergic beta-agonists and that this response is mediated by cAMP. In rat kidney slices, Churchill and Churchill (17) observed that isoprenaline stimulated renin secretion, with cAMP acting as second messenger. All the known cellular responses to beta adrenoreceptor activation are mediated by an increase in cAMP resulting from the stimulation of adenylate cyclase. Our results demonstrate the presence in human JGC of histamine $\mathrm{H}_{2}$-receptors through which the cells respond to histamine by a stimulation in prorenin secretion. The inhibition of the stimulatory effect of histamine on cAMP release by cimetidine but 
not by diphenhydramine indicates that the effect of histamine is mediated by $\mathbf{H}_{2}$-receptors linked to adenylate cyclase. Sperk et al. (29), who examined $\mathrm{H}_{2}$-receptor binding to isolated glomerular cells using $\left[{ }^{3} \mathrm{H}\right]$ cimetidine as ligand, concluded that histamine $\mathrm{H}_{2}$-receptors were present on isolated glomerular cells. In the isolated perfused rat kidney, Schwertschlag and Hackenthal (30) demonstrated that the stimulation of renin secretion by histamine was mediated by $\mathrm{H}_{2}$-receptors. Sedor and Abboud (31) investigated the in vitro effect of histamine on cAMP accumulation in cultured rat mesangial cells and reported the presence of a histamine $\mathrm{H}_{2}$-receptor dependent on adenylate cyclase. In our system, the variations in cAMP release were small, but Sedor and Abboud (32) observed that the increase in cAMP accumulation in response to histamine was smaller in human glomeruli than in rat glomeruli. The present work demonstrates the presence in cultured human JGC of specific $\mathbf{H}_{2}$-histamine-receptors that are also dependent on adenylate cyclase.

In addition, our study shows that kinins can stimulate prorenin secretion in vitro, thus indicating the presence of kinins receptors in human JGC. In our system, we found that prorenin secretion in response to equimolar concentrations of bradykinin, Lys-bradykinin, or des-Arg ${ }^{9}$-bradykinin was virtually the same. Both kinins and $\beta$-adrenergics stimulated renin secretion to a similar degree, as reported by Beierwaltes et al. (33) in studies using isolated rat glomeruli. However, the effect of des-Arg-bradykinin on renin secretion does not agree with the last result of Beierwaltes et al. (33), who reported that this analogue did not affect renin release in isolated rat glomeruli. They described des-Arg ${ }^{9}$-bradykinin as an inactive kinin analogue in their system, but we can support the hypothesis that in cell culture, one of the most simple systems, it is active. Our results show that the response to kinins is mediated by cAMP and suggest that the kinin receptors in human JGC are dependent on adenylate cyclase.

Although substance $P$ was an inhibitor of prorenin secretion, no variation in cAMP release was detected. Gullner et al. (34) also showed an inhibitory effect of substance $P$ on renin release in anesthetized dog and suggested it had a direct effect on the JGC. The results obtained with cAMP are in opposition to the suggestion by Pernow (35) that the substance P may exert its effect on water reabsorption by an adenylate cyclase mechanism.

This paper demonstrates that prorenin secretion in the human transfected JGC is modulated by various pharmacological agents, even if the changes in prorenin secretion are less marked than in vivo models (28). In these cells, which provided a permanent source of human prorenin secretion, the adenylate cyclase system remained intact during culture. The results of this study of the regulation of in vitro human prorenin secretion by these cells support the hypothesis that cAMP is the second messenger and $\mathrm{Ca}_{\mathrm{i}}{ }^{2+}$ the final messenger involved in renin secretion. The cell culture model described here is therefore a useful tool for investigating various aspects of renin biosynthesis and secretion at the cellular level, under controlled conditions.

\section{Acknowledgments}

We thank Dr. I. Darby, Dr. K. Keeton, and W. B. Campbell for helpful discussions, N. Braure and F. Lopez for typing the manuscript, and A. Boisquillon for art work.

\section{References}

1. Keeton, T. K., and W. B. Campbell. 1980. The pharmacological alteration of renin release. Pharmacol. Rev. 32:81-227.

2. Hackenthal, E., V. Schwertschlag, and R. Taugner. 1983. Cellular mechanisms of renin release. Clin. Exp. Hypertens. Part A, Theory and Practice. A5(Suppls. 7 and 8):9975-9993.

3. Kurtz, A., J. Pfeilschifter, and C. Bauer. 1984. Is renin secretion governed by the calcium permeability of the juxtaglomerular cell membrane? Biochem. Biophys. Res. Commun. 124:359-366.

4. Kurtz, A., J. Pfeilschifter, A. Hutter, C. Buhrle, R. Nobiling, R. Taugner, E. Hackenthal, and C. Bauer. 1986. Role of protein kinase C in inhibition of renin release caused by vasoconstrictors. Am. J. Physiol. 259(Cell. Physiol. 19):C563-C571.

5. Pinet, F., M. T. Corvol. F. Dench, J. Bourguignon, J. Feunteun, J. Ménard, and P. Corvol. 1985. Isolation of renin-producing human cells by transfection with three simian virus $\mathbf{4 0}$ mutants. Proc. Natl. Acad. Sci. USA. 82:8503-8507.

6. Barnes, D., and G. Sato. 1980. Methods for growth of cultured cells in serum-free medium. Anal. Biochem. 102:255-270.

7. Ménard, J., J. Bews, and C. Heusser. 1984. A multirange ELISA for the measurement of plasma renin in humans and primates. $J$. Hypertension. 2(Suppl. 3):275-278.

8. Caillat, H. L., M. S. Racine-Weisbuch, and M. A. Delaage. 1983. Adenosine 3',5' cyclic AMP monophosphate assay at $10^{-15}$ mole level. Anal. Biochem. 56:394-407.

9. Lindop, G. B. M., and D. S. Gardiner. 1986. The human renin secreting cell. Morphologic study. Ann. Endocrinol. (Paris). 47:133144.

10. Catanzaro, D. F., J. J. Mullins, and B. J. Morris. 1983. The biosynthetic pathway of renin in mouse submandibular gland. J. Biol. Chem. 258:7364-7368.

11. Pratt, R. E., A. J. Ouellette, and V. J. Dzau. 1983. Biosynthesis of renin: multiplicity of active and intermediate forms. Proc. Natl. Acad. Sci. USA. 80:6809-6813.

12. Schulster, D., J. Orly, G. Seidel, and M. Schramm. 1978. Intracellular cyclic AMP production enhanced by a hormone receptor transferred from a different cell. J. Biol. Chem. 253:1201-1206.

13. Rindler, M. J., M. M. Bashor, N. Spitzer, and M. H. Saier. 1978. Regulation of adenosine $3^{\prime}, 5^{\prime}$-monophosphate efflux from animal cells. J. Biol. Chem. 253:5431-5436.

14. Seamon, K., and J. Daly. 1981. Activation of adenylate cyclase by the diterpene forskolin does not require the guanine nucleotide regulatory protein. J. Biol. Chem. 256:9799-9801.

15. Schwertschlag, V., and E. Hackenthal. 1982. Forskolin stimulates renin release from the isolated perfused rat kidney. Eur. J. Pharmacol. 84:111-113.

16. Wells, J. N., and G. L. Kramer. 1981. Phosphodiesterase inhibitors as tools in cyclic nucleotide research: a precautionary comment. Mol. Cell. Endocrinol. 23:1-9.

17. Churchill, P. C., and M. C. Churchill. 1982. Isoproterenol stimulated renin secretion in the rat: second messenger roles of $\mathrm{Ca}$ and cyclic AMP. Life Sci. 30:1313-1319.

18. Fray, J. C. S., D. J. Lush, and A. N. D. Valentine. 1983. Cellular mechanisms of renin secretion. Fed. Proc. 42:3150-3154.

19. Churchill, P. C. 1985. Second messengers in renin secretion. Am. J. Physiol. 249(Renal Fluid Electrolyte Physiol. 18):F175-F184.

20. Burnett, J. C., J. P. Granger, and T. J. Opgenorth. 1984. Effects of synthetic atrial natriuretic factor on renal function and renin release. Am. J. Physiol. 247(Renal Fluid Electrolyte Physiol. 16):F863-F866.

21. Opgenorth, T. J., J. C. Burnett, J. P. Granger, and T. A. Scriven. 1986. Effects of atrial natriuretic peptide on renin secretion in non filtering kidney. Am. J. Physiol. 250(Renal Fluid Electrolyte Physiol. 19):F798-F801.

22. Villareal, D., R. H. Freeman, J. O. Davis, K. M. Verburg, and R. C. Vari. 1986. Renal mechanisms for suppression of renin secretion by atrial natriuretic factor. Hypertension. 8(Suppl. 2):II-28-II-35.

23. Hackenthal, E., R. E. Langaud, and C. P. Bührle. 1985. Atrial 
natriuretic factor stimulates renin release from the isolated perfused rat kidney. J. Hypertension 3(Suppl. 3):S323-S325.

24. Hiruma, M., F. Ikemoto, and K. Yamamoto. 1986. Rat atrial natriuretic factor stimulates renin release from renal cortical slices. Eur. J. Pharmacol. 125:151-153.

25. Obana, K., M. Naruse, K. Naruse, H. Sakurai, H. Demura, T. Inagami, and K. Shizume. 1985. Synthetic rat atrial natriuretic factor inhibits in vitro and in vivo renin secretion in rats. Endocrinology. 117:1282-1284.

26. Kangawa, K., and H. Matsuo. 1984. Purification and complete aminoacid sequence of $\alpha$-human atrial natriuretic polypeptide ( $\alpha$ hANP). Biochem. Biophys. Res. Commun. 118:131-139.

27. Kurtz, A., R. D. Bruna, J. Pfeilschifter, R. Taugner, and C. Bauer. 1986. Atrial natriuretic peptide inhibits renin release from juxtaglomerular cells by a cGMP-mediated process. Proc. Natl. Acad. Sci. USA. 83:4769-4773.

28. Fray, J. C. S., and C. S. Park. 1986. Forskolin and calcium: interactions in the control of renin secretion and perfusate flow in the isolated rat kidney. J. Physiol. 375:361-375.
29. Sperk, G., E. Ratzenhofer, G. Simbruner, H. Coradello, A. Pollak, and G. Lubec. 1980. Evidence for $\mathrm{H}_{2}$-receptor activity on glomerular cells. Renal Physiol. 3:152-155.

30. Schwertschlag, U., and E. Hackenthal. 1982. Histamine stimulates renin release from the isolated perfused rat kidney. NaunynSchmiedebergs Arch. Pharmakol. 319:239-242.

31. Sedor, J. R., and H. E. Abboud. 1985. Histamine modulates contraction and cyclic nucleotides in cultured rat mesangial cells. $J$. Clin. Invest. 75:1679-1689.

32. Sedor, J. R., and H. E. Abboud. 1984. Actions and metabolism of histamine in glomeruli and tubules of the human kidney. Kidney Int. 26:144-152.

33. Beierwaltes, W. H., J. Prada, and O. A. Carretero. 1985. Kinin stimulation of renin release in isolated rat glomeruli. Am. J. Physiol. 248(Renal Fluid Electrolyte Physiol. 17):F757-F761.

34. Gullner, H. G., W. B. Campbell, and W. A. Pettinger. 1979. Effects of substance $P$ on renin release and renal function in anesthetized dogs. Life Sci. 24:237-246.

35. Pernow, B. 1983. Substance P. Pharmacol. Rev. 35:86-141. 